\title{
عوائق البحث العلمي في الجامعات العربية
}

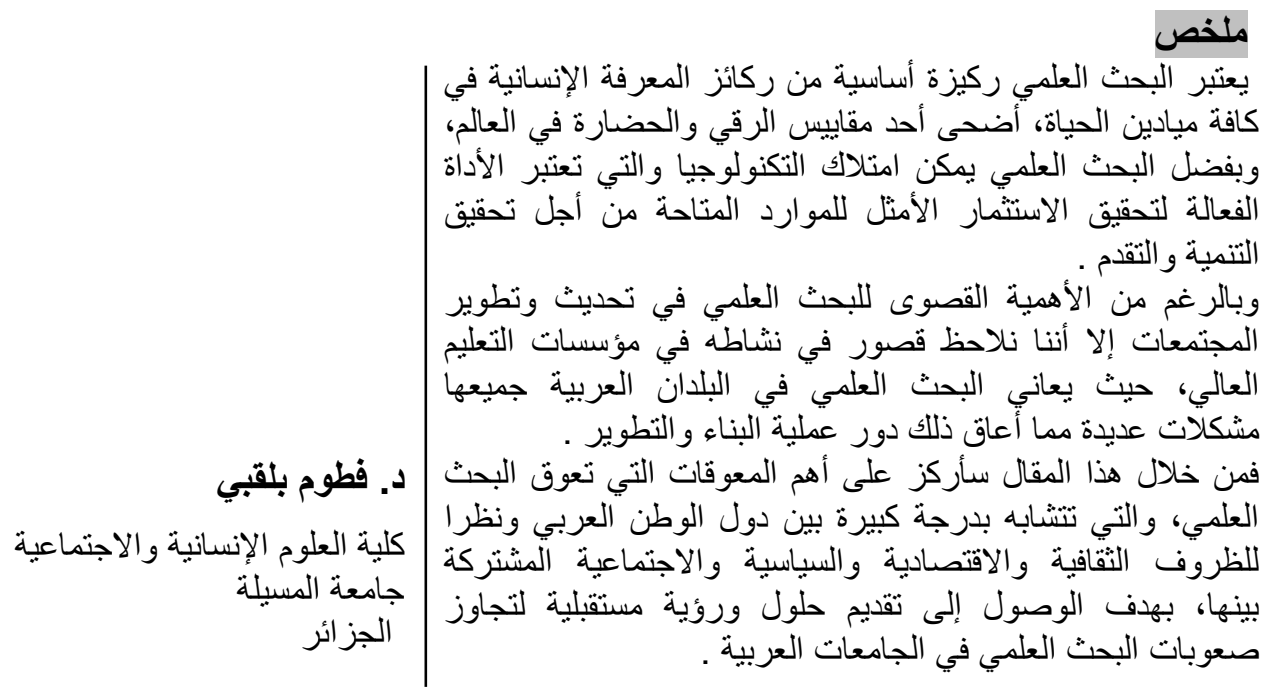

\section{مقدمة Résumé}

La Recherche Scientifique est un

منث السمات التي يتميز بها عالمنا اليوم السباق المتسارع في مجال العلم والتكنولوجيا،

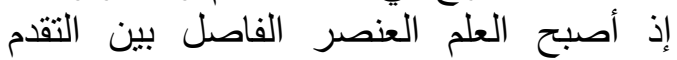
والتخلف، و أنه بقدر ما تبذله الأمم في سبيل البحث العلمي من جهد ومال، بقدر ما يكون تقدها، وبقدر ما تتمكن من معطياته وتطبيقاته

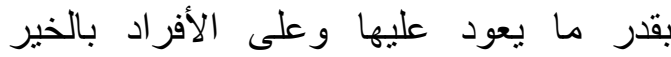
والرفاهية، فقد انقضى ذللك العصر الذي كان

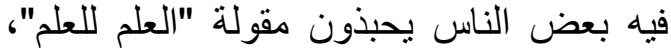
فقد أصبح العلم الآن لصالح المجتمع الذي يعمل

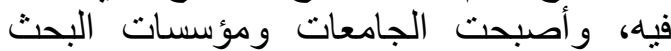

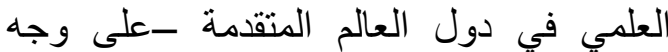
الخصوص- ذات وظائف محددة أهمها حل مشكلات المجتمع الذي توجد فيه. facteur essentiel de développement et de civilisation dans le monde. Grâce à elle, s'est développée la technologie, qui est un outil efficace dans la réalisation de l'investissement idéal des ressources disponibles pour le développement et le progrès. Dans les pays arabes, la recherche scientifique souffre de divers problèmes, ce qui a empêché la réalisation du processus de développement (au sens large du mot) de ces pays.

Dans cet article, nous présentons les principaux obstacles qui empêchent la recherche scientifique d'atteindre ses objectifs au niveau des établissements du supérieur dans les pays arabes. 


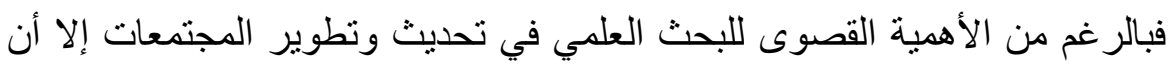

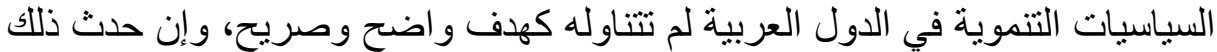

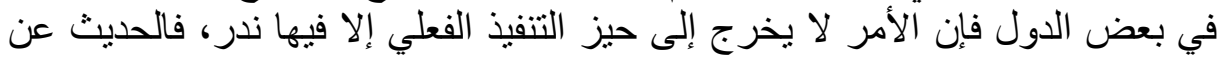
عو ائد البحث العلمي دون تناول لطبيعة السياق التنموي الذي لأي يتحرك فيه ويؤثر فيه يعتبر هر اء.

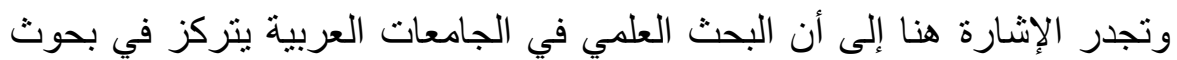

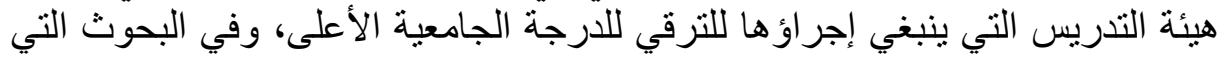

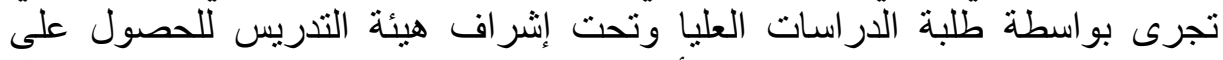

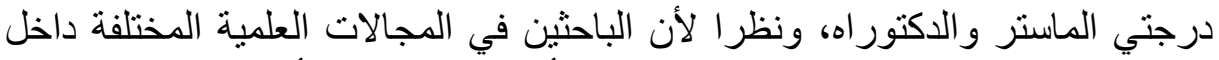

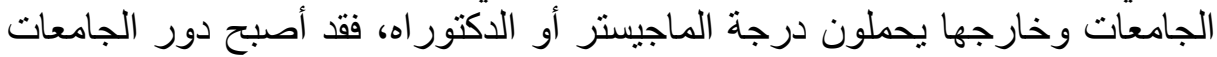

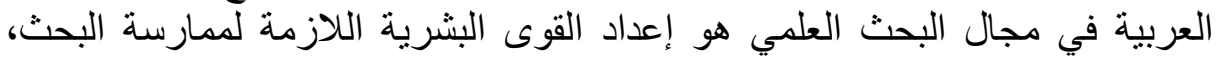

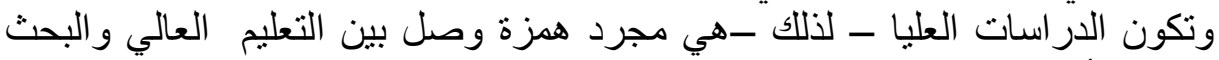

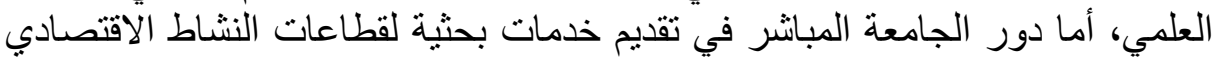

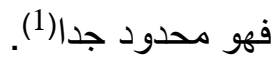

و الحقيقة ،فإن الخدمات البحثية المقدمة لقطاعات النشاط الاقتصادي ليست محدودة

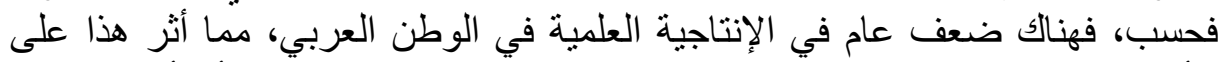

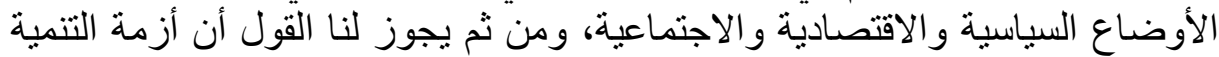

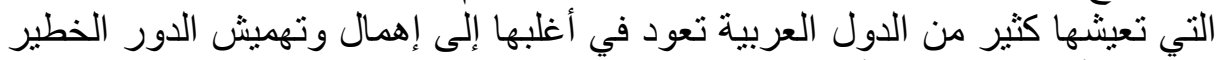

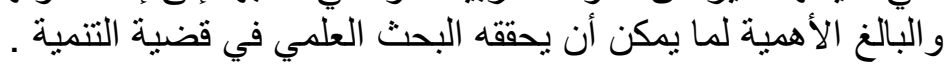

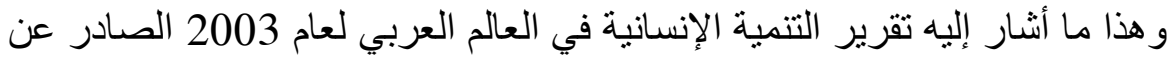

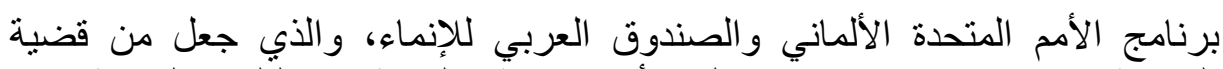

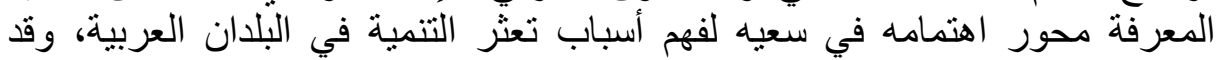

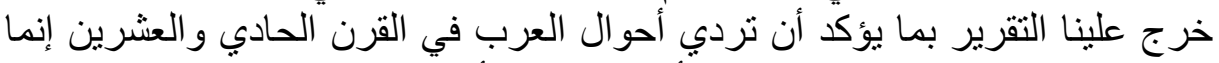

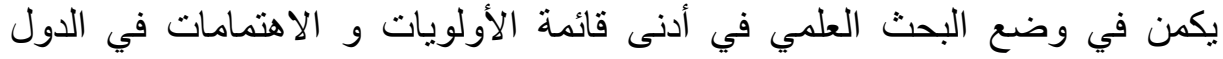
العربية (2)

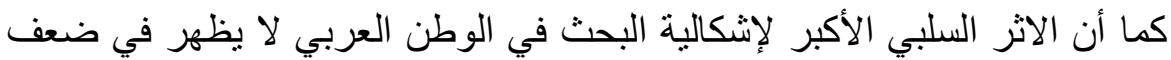

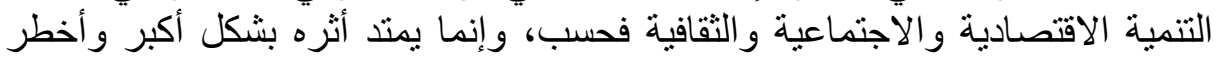

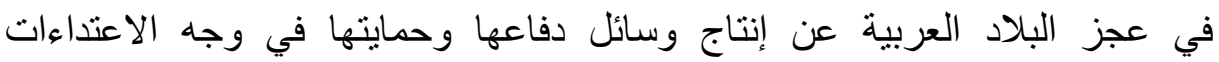

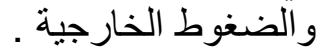

وفي ضوء ما سبق يمكن القول أن البحث العلمي في الوطن العربي يواجه كثيرا

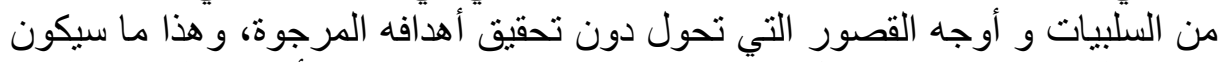
محور الدراسة في هذا المقال الذي سيتم من خلاله التطرق إلى أهداف البحث الهـ العلمي 


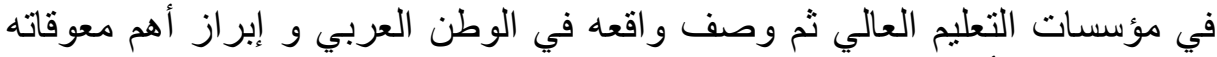

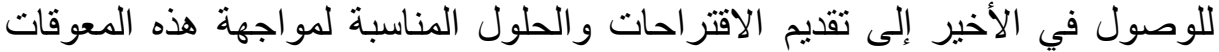

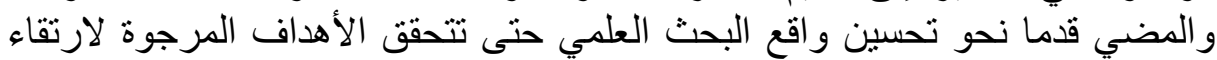

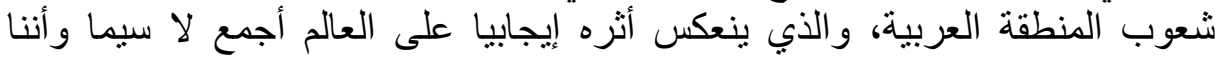

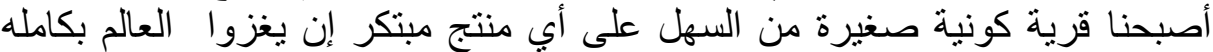
بسر عة فائقة في ساعات معدودة.

1- مفهوم البحث العلمي :

يعرف البحث العلمي على أنه" التقصي المنظم بإتباع أساليب ومناهج علمية

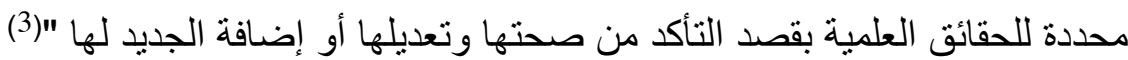

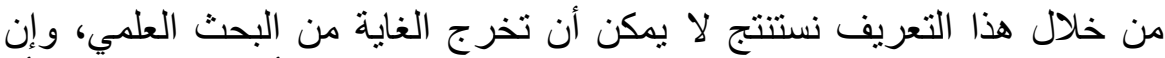

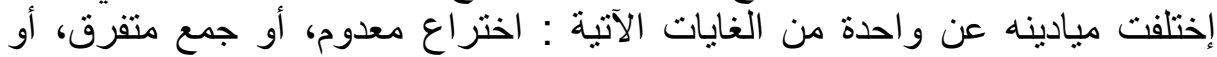

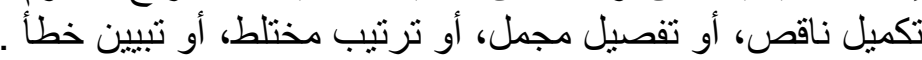

ويعرفه الأستاذ الدكتور فضيل دليو في كتابه: (أسس البحث وتثنياته في العلوم

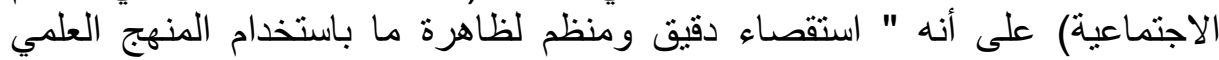
بتقنياته المختلفة الكمية والكيفية، وذللك بهدف اكتشاف حقائق وقو اعد عامة يمكن

التحقق منها، ويمكن الاستفادة منها في الحياة العلمية و العملية" (4). يشير هذا التعريف إلى أن هدف البحث العلمي هو اكتشاف قواعد عامة يمكن التحقق منها مستقبلا و الاستفادة منها وذلك يكون بطريقة علمية ومنهجية منظمة.

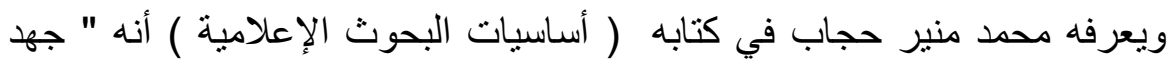
فكري، يتم بمنهجية منظمة مدروسة ويفرز نتائج منطقية موضو عية يمكن توظيفها في حل مشاكل المعرفة و الإنسان والمجتمع "(5) مدروسة يبين هذا التعريف أن هدف البحث العلمي هو التوصل إلى حل مشاكل المعرفة و الإنسان و المجتمع، وذللك بمر اعاة عامل التنظيم المتكامل لخطو ات البهي البحث العلمي.

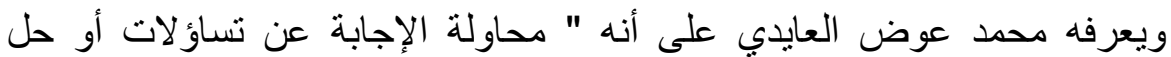
مشكلات أو لاكتشاف معارف جديدة أو اختر اع و وابتكار أشياء حديثة لم تكن معروفة الإنة

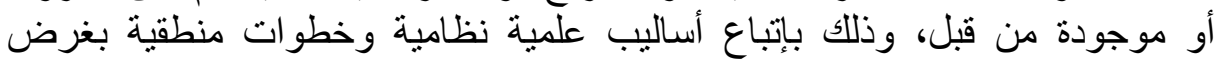
الوصول إلى المعلومات ومعارف جديدة عن طريق بذل الجهود في السعي وراء

المعارف وجمع المعلومات وتحليلها " (6).

أضاف هذا التعريف للتعريفات السابقة أن هدف البحث العلمي هو الوصول إندان إلى ابتكار ات و إبداعات أو اختر اعات جديدة في مجال معين. 
كما يعرف على أنه " نشاط علمي منظم، وطريقة في التفكير، و وأسلوب للنظر في مني

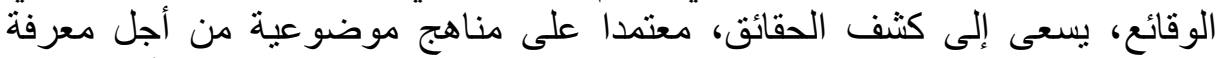
الارتباط بين هذه الحقائق، ثم استخلاص المبادئ العامة و القوانين العامة أو القوانين

التفسيرية " (7) - (7)

ويعتبر هذا التعريف من التعاريف الثاملة في مفهوم البحث العلمي وذلك

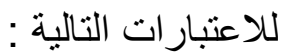

- - أوضح هذا التعريف أن البحث العلمي عملية منظمة يتم بمراحل مرتبة ومتسلسلة وفق نظام معين وخطة مرسومة، فيستخدم الأساليب العلمية النظامية و الطرق و المناهج البحثية الموتقة. - - أوضح التعريف أن البحث العلمي يرتبط بالمشكلات الواقعية الموجودة في

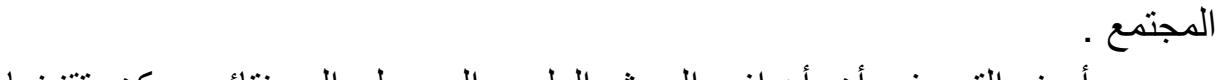
- - أبرز التعريف أن أهداف البحث العلمي الوصول إلى نتائج بمكن تقنينها و ت و تعيمها وتتفيذها.

\section{ـأهداف البحث العلمي في مؤسسات التعليم العالي :}

ون المعروف أن مؤسسات التعليم العالي لها ثلاثثة أدوار رئيسـة تـعلق بالتدريس،

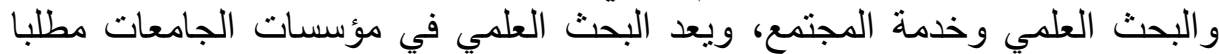

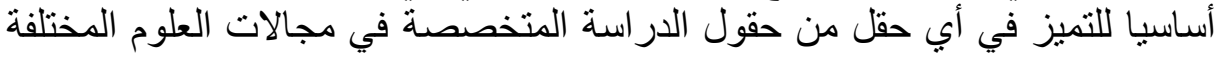

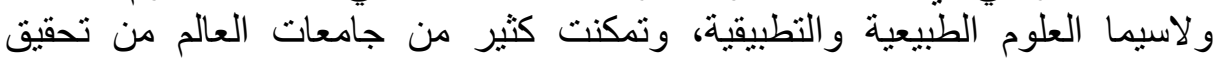

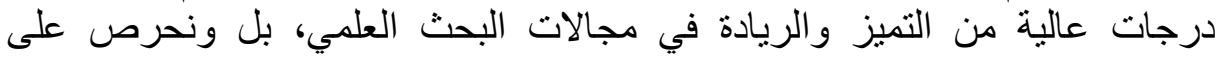
استمرار هذا التميز والريادة في تلك المجالات التيات من خلال باحثين متميزين يكون

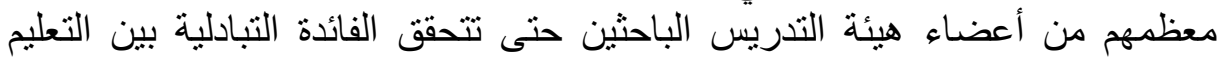

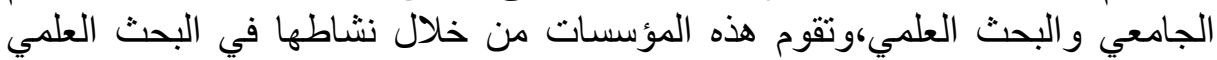

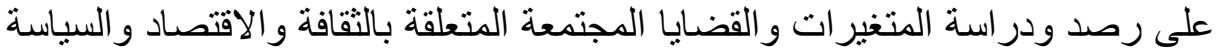

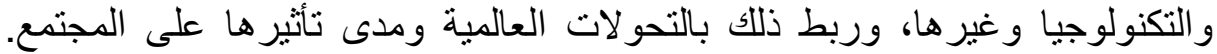

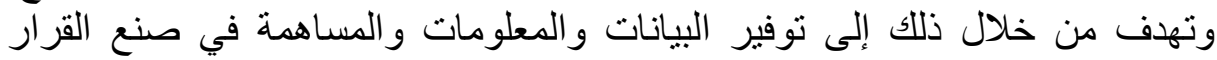

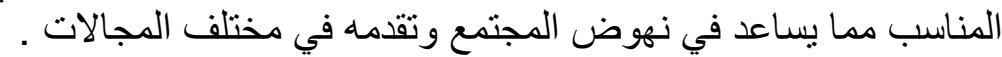

وتسعى الجامعات والكليات من عملها في البحث العلمي إلى تحقيق عدد من

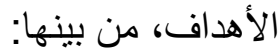

إعداد جيل من الباحثين المتميزين .

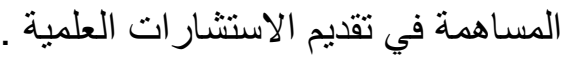
إيجاد الحلول العلمية للمشكلات المتعلقة بخطط التطوير و التنمية .

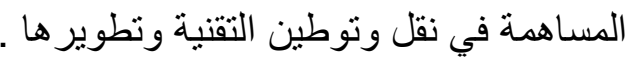


الرقي بمستوى الدر اسات العليا.

توطيد العلاقة مع المجتمع المحلي وشركاء القطاع الخاص الخاص .

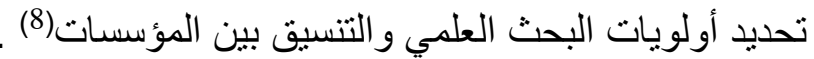

ولتفعيل دور مؤسسات التعليم العالي في البحث العلمي فلابد من وجود ترابط

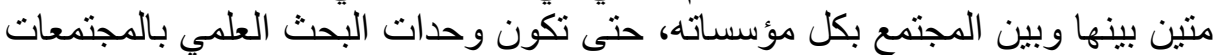

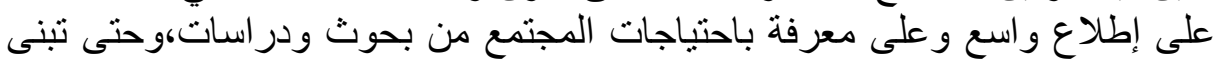
الفرضيات البحثية على الواقع الحقيقي لمشكلات المجتمع والتحديات التي تواجنهات التهات مؤسساته .

\section{3- واقع البحث العلمي في الوطن العربي :}

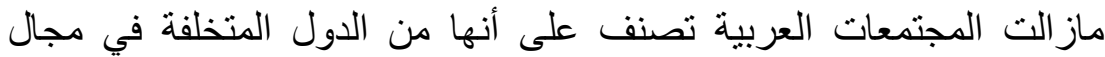

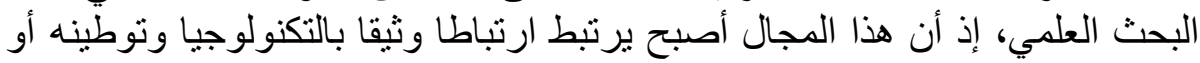

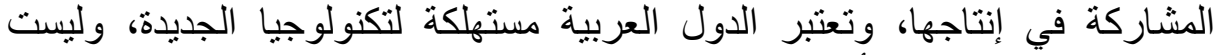

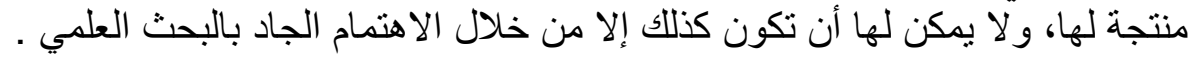

و هناك اتفاق دولي حول نسبة الإنفاق على البحث العلمي لا تتجاوز قيمته 1\%

من الناتج المحلي الإجمالي(9)، فمستوى الإنفاق على البحث العلمي و التقني في الوطن

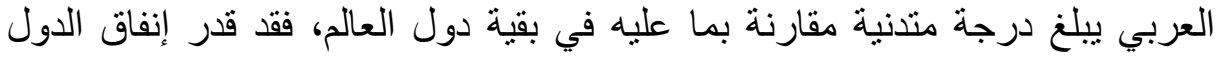

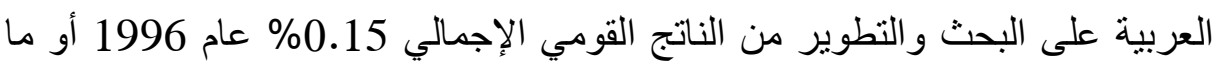

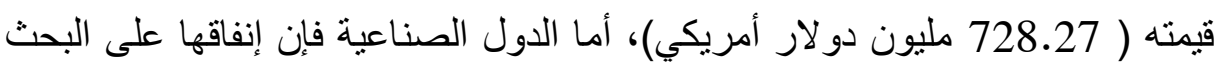

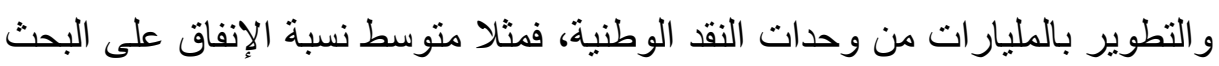

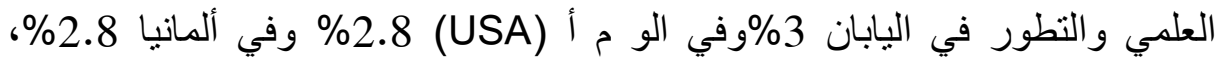
وكنتيجة فإن نسبة الإنفاق في البحث و التطوير في الدول الصناعية تتر اوح بين 2\% و 5\% بينما لا تتجاوز هذه النسب في جميع الدول العربية 1\%.ويأتي الإنفاق على البحث والتطوير من مصادر حكومية بنسبة90\%، و لا تخصص القطاعات الإنتاجية و الخدماتية سوى 3\%قط من هذه المصادر بينما تزيد هذه النسبة في الدول المتقدمة ولهاب

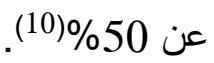

وبالمقارنة مع مجموعة دول النمور الآسيوية التي نجحت وفي فترة وجيزة

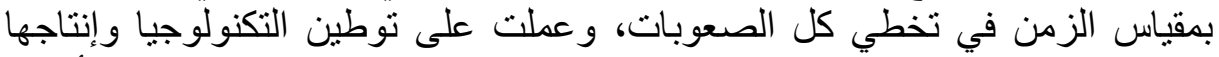

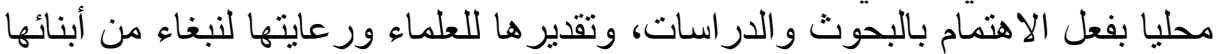

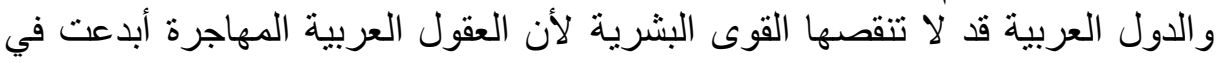


الدول المتقدمة عندما وجدت من يتبناها ويرعاها، ويوفر لها البيئة الملائمة للعمل

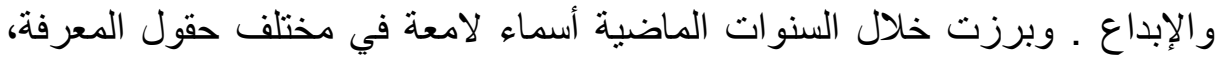

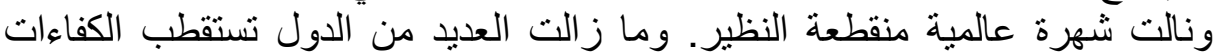
البشرية العربية من ذوية الاختهة تكنولوجيا الاتصال و المعلومات(11).

انطلاقا مما سبق نستتتج ضآلة الانفاق على البحث العلمي وتدني مستوى توظيف

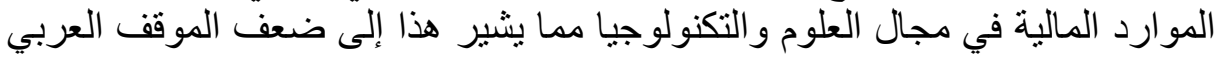

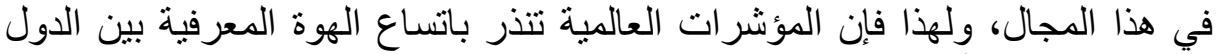

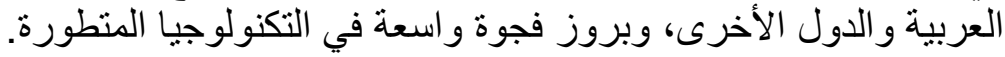
- إثكاليات البحث العلمي في الجامعات العربية :

بعد القراعة والاطلاع على مزيد من أدبيات الموضوع، بما تحويه من دراسات

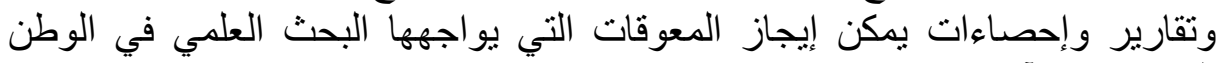

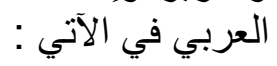

$$
\begin{aligned}
& \text { - - تدني مستوى الإنفاق على البحث العلمي . }
\end{aligned}
$$

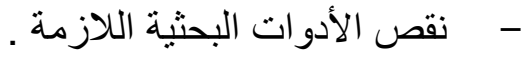

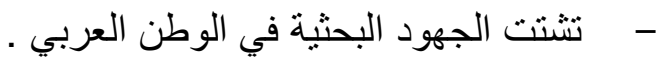

$$
\begin{aligned}
& \text { - - عدم توفر البيئة والظروف البحثية الملائمة . } \\
& \text { - - عدم ربط الجهود البحثية بأهداف التنمية الثاملة . }
\end{aligned}
$$

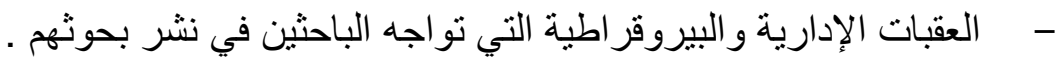

ولقد حدد غانم(2000م) عدد من المعيقات التي تواجه البحث العلمي في الوطن

$$
\text { العربي ومن أبرز ها ما يلي(12): }
$$

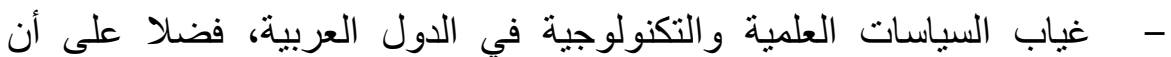

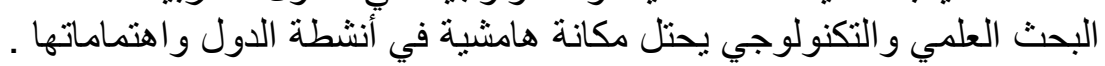

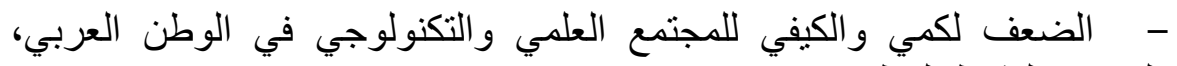
و عزلته عن النشاط الوطني و الإنمائي . للهن

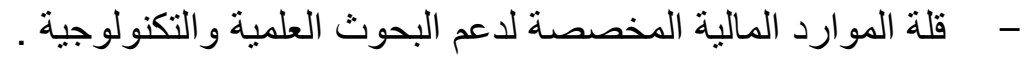

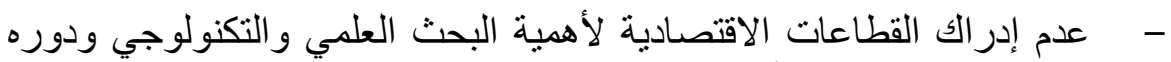

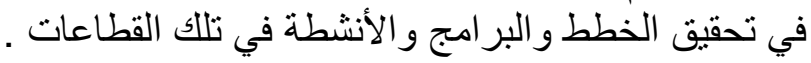
- ضعف مر اكز المعلومات العلمية، وتدني خدمات التوثيق و المكتبات . 
- - عدم توفير المناخ الملائم لإجر اء البحوث و انتشار البيروقر اطية وقلة الحو افز

- - - التبعية العلمية و التكنولوجية للدول المتقدمة .

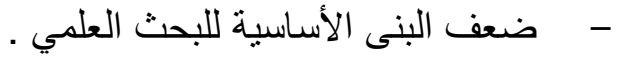

- - مجرة الكفاءات العربية إلى الخارج ل

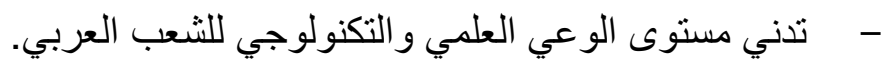

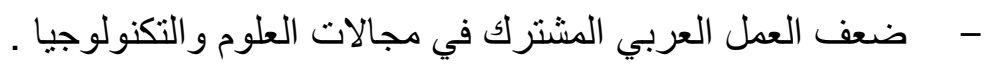

كما أثنار البياتي (2006) عن واقع البحث العلمي في الوطن العربي وبيئته العلمية

ويصفها بأنها حركة نمطية وتقليدية ومتخلفة لأسباب عديدة أبرز ها(13):

$$
\text { - ضعف الإنفاق على البحث العلمي. }
$$

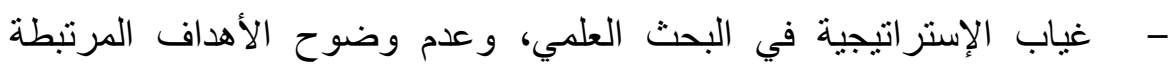
بحاجات المجتمع وظروفه و إمكاناته.

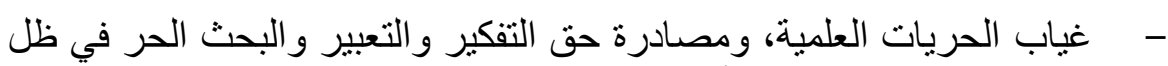

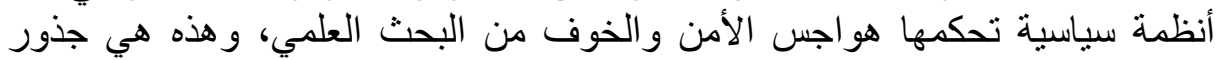
أزمة البحث العلمي في الوطن العربي العبن الامن

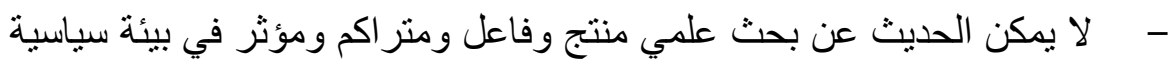

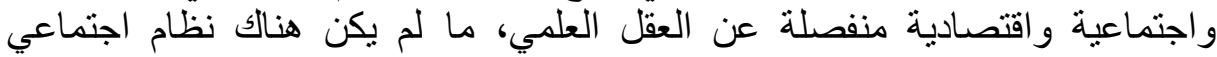

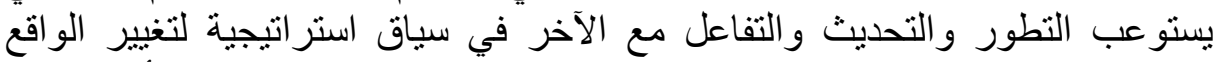

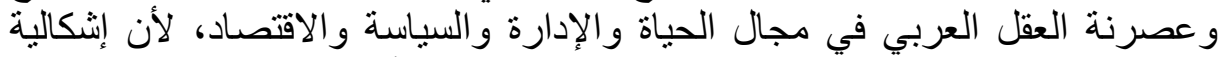

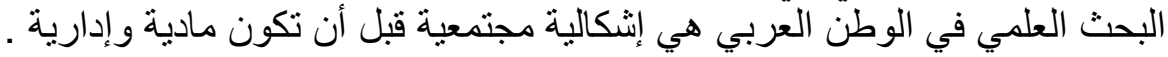

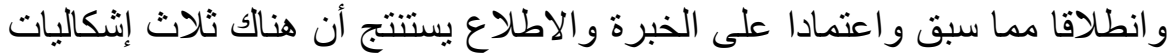

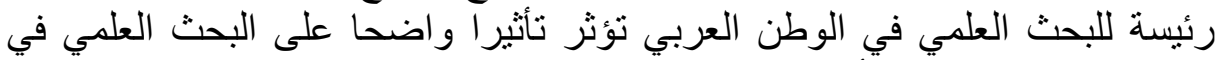

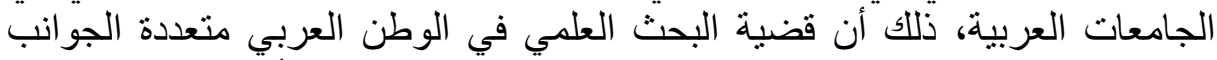

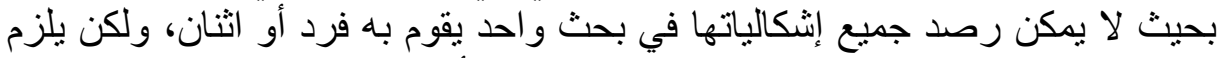

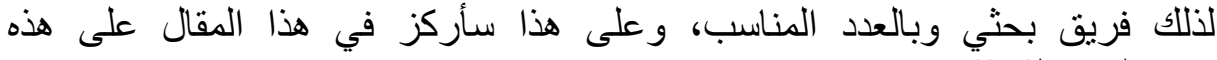

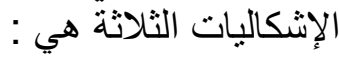

$$
\begin{aligned}
& \text { - - مإنكالية السيطرة السياسية . } \\
& \text { - - مثنالية ضعف التمويل . } \\
& \text { - - إثكالية هجرة العقول والكفاءات العربية . } \\
& \text { أ- البحث العلمي وإثكالية السيطرة السياسية : }
\end{aligned}
$$

من شروط الازدهار والبحث في أي مجتمع تو افر بيئة مشجعة للإبداع، ومن غير 
المتوقع أن تتو افر تلك البيئة في ظل نظم سياسة غير ديموقراطية تهتم فقط بمصالحها

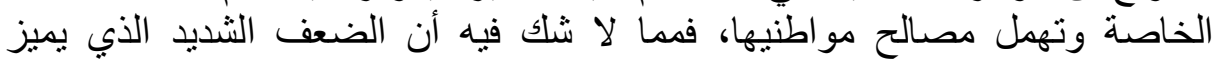

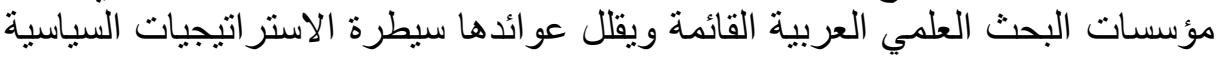

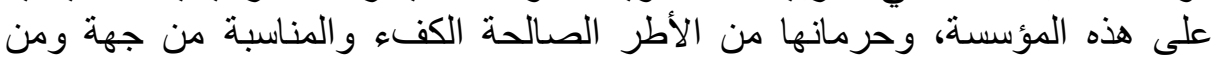

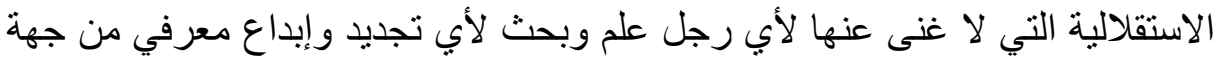

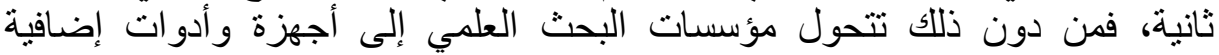

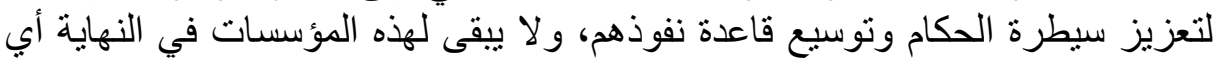
علاقة بميدان البحث العلمي(14).

فإذا رجعنا إلى القوانين المنظمة لمؤسسات التعليم العالي والبحث العلمي في

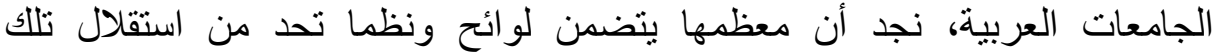

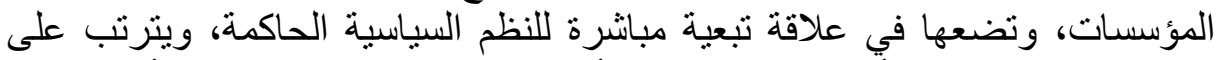

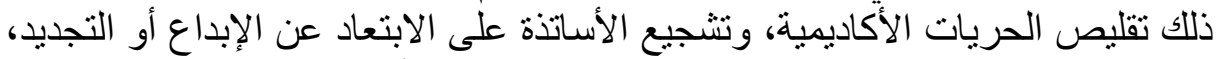

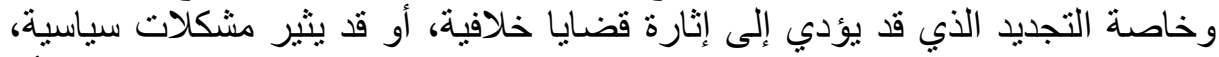

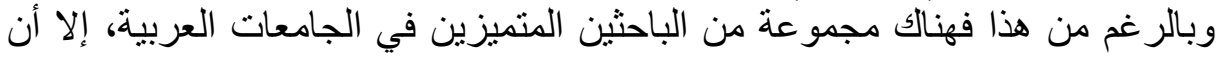

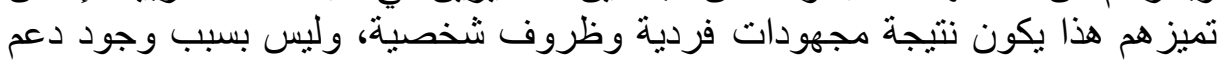

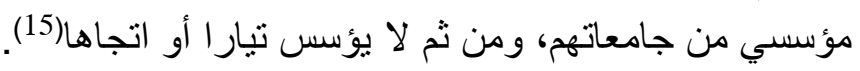

و ون هنا يشكل إخضاع الجامعات العربية - باعتبار ها أحد أهم وأبرز المؤسسات

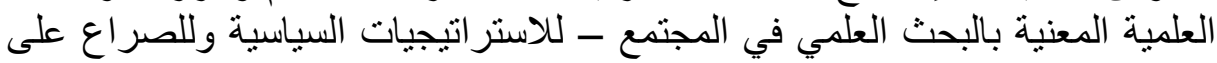

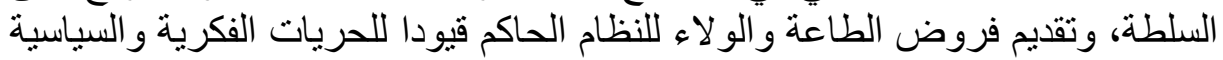

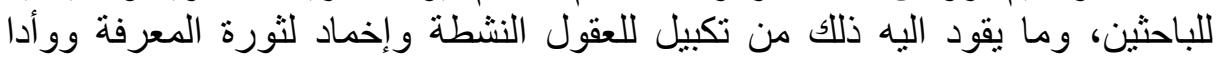

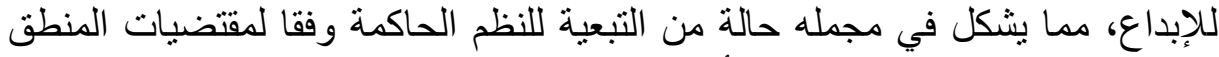
السياسي الحاكم، وليس وفقا لخطة أو سياسة علمية حكيمة. وقد لخص البروفيسور الفرنسي فرانسوا جاكوب الحاصل على جائزة نوبل في الطب 1965 ذلك الوضع قائلا : " من المؤسف أن العلم لا يهر عالم السياسة "(16). فالحكومات تهمها النتائج العلمية والمباشرة والنافعة التي يمكن ترجمتها لأرقام

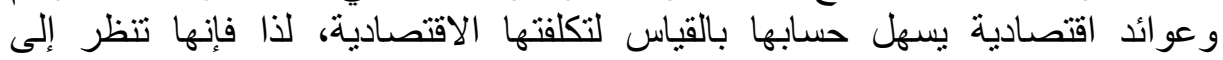

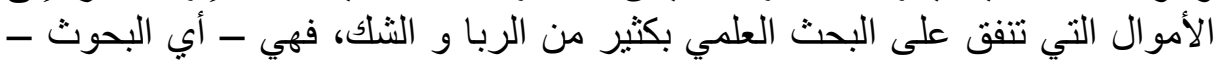

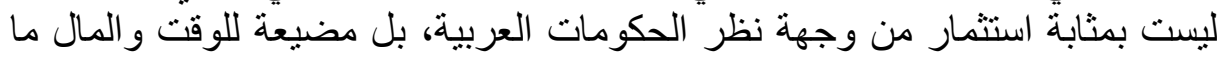

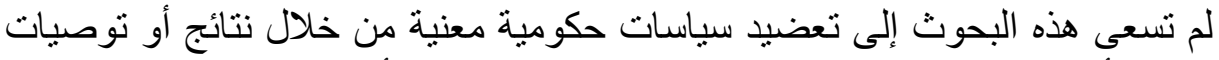
معينة أو الإتيان بعوائد اقتصادية تسهم في تخفيض أعباء الحكومة في تمويل البحوث(17).

باختصار، فان الكثير من البلدان العربية لا تزال تفقتر إلى الالتزام السياسي تجاه 


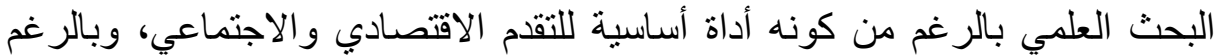

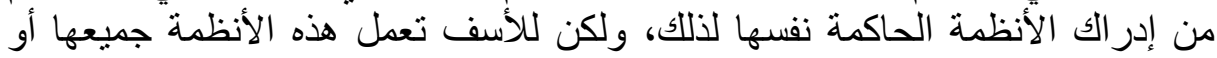

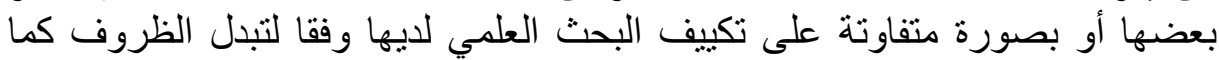

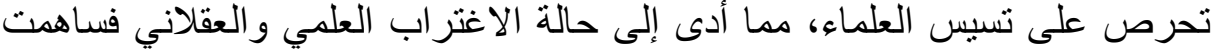
في تفريد المنجز العلمي والعقلاني، ولم تفسح المجال لتوالي التي أجيال تتولى توطيد

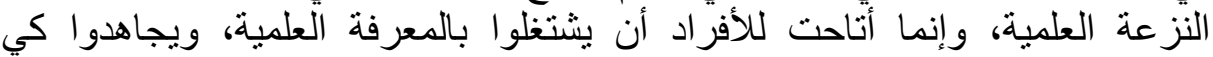

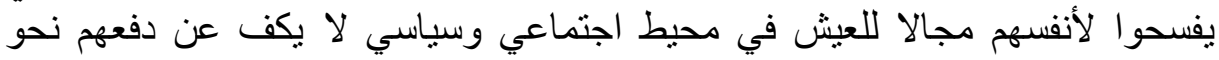

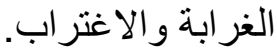

\section{ب- البحث العلمي و إثكالية ضعف التمائ التمويل:}

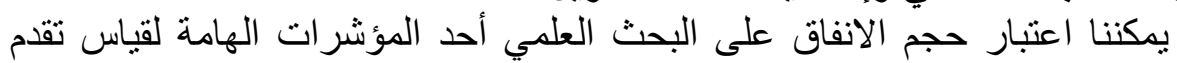

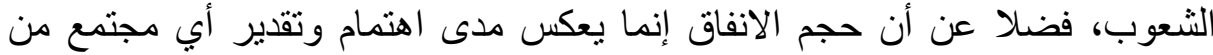

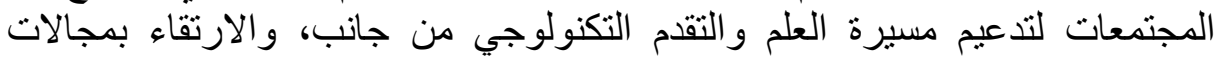

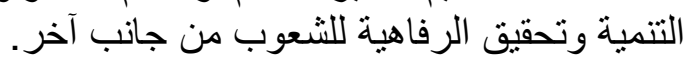

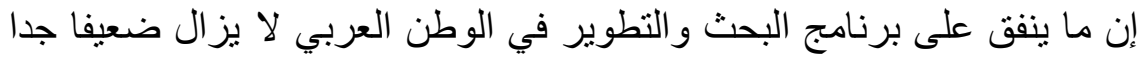

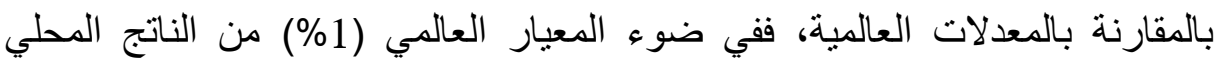

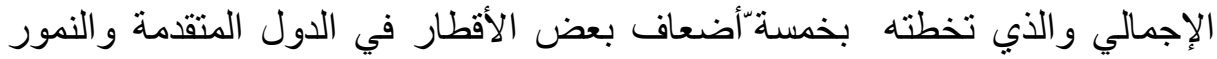

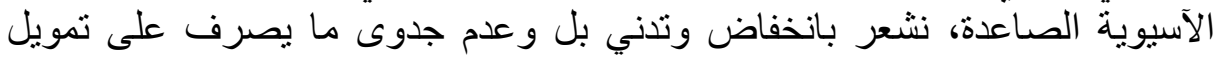

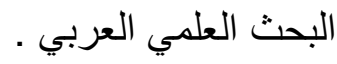

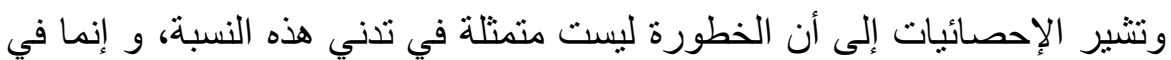

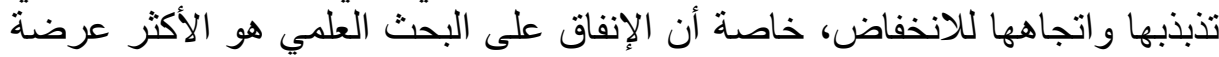

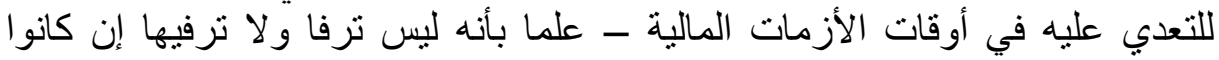
متخذو القرار ماز الوا يفكرون بهذا الأسلوب - بعد أن بلغ حجم هذا الإنفاق إلى 575 مليون دولار عام 1985، انخفض بشكل مطلق إلى 548 مليون دولار عام 1996 ـ

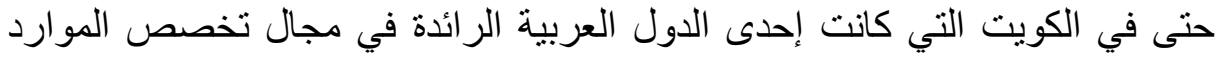
للبحث العلمي، تم اقتطاع جزء كبير من ميز انيته وتوجيهه للأنشطة العسكرية(18). ومن هنا يمكن القول أن تراجع الإنفاق على البحث العلمي في الوطن العربي يعد العادي

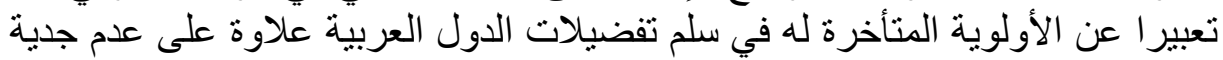
كثير من البرامج البحثية فيه .

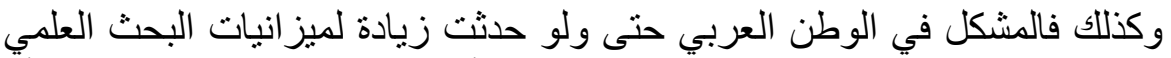

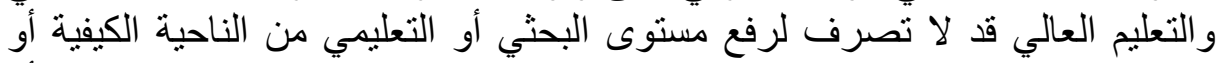

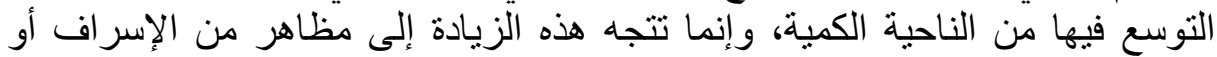

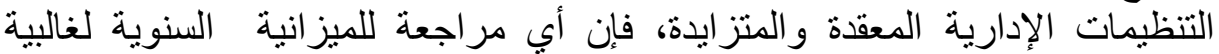




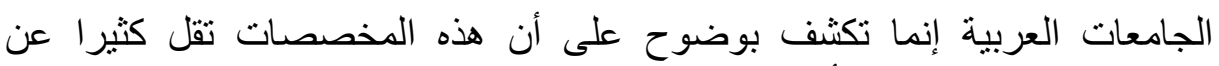

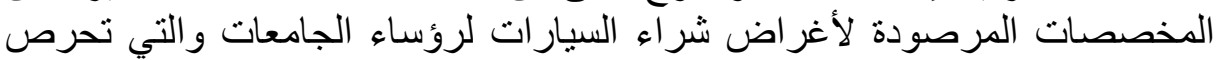
غالبيتهم على تجديدها كل عام.

ويشير ملحس (2005) أن الباحثين الجامعيين يعانون من إثكالات ونو اقص تعيق

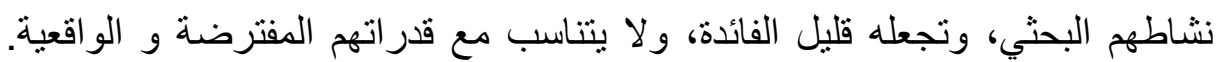

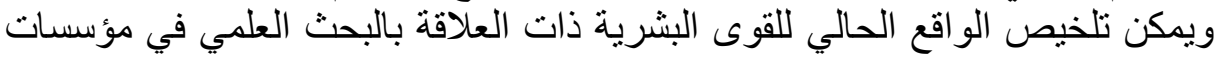
التعليم العالي بما بليم(19):

- - قلة عدد الباحثين المتفر غين بالر غم من وجود نظام خاص بهم في الجامعات.

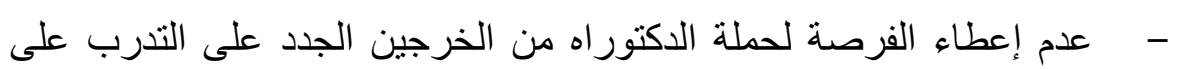

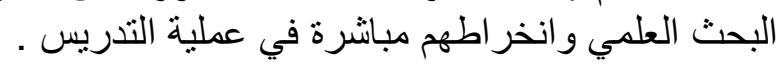

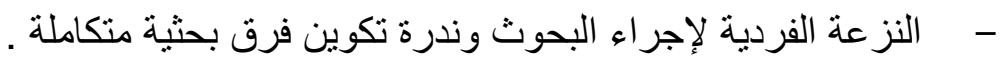

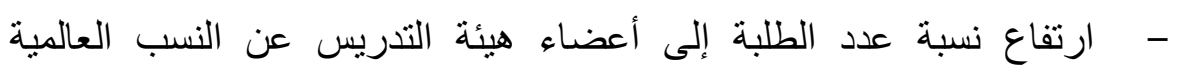
المتعارف عليها . أنغاع - - منشغال عدد كبير من أعضاء هيئة التدريس في العمل الإضافي .

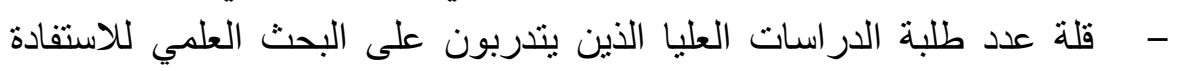

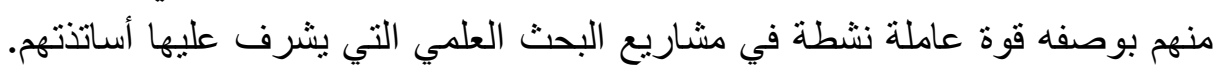

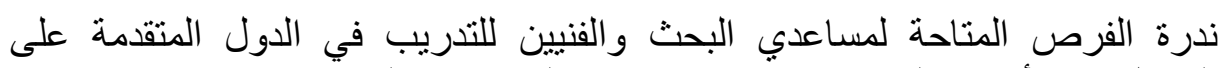

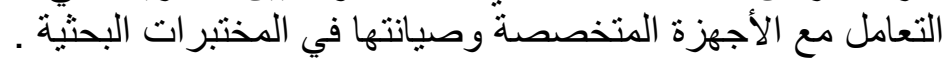
ج- البحث العلمي وإثكالية هجرة العقول والكفاعات العربية :

تعد قضية هجرة العقول والكفاءات من مشكلات التي تستأثر باهتمام الدول

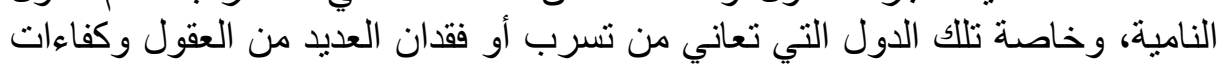

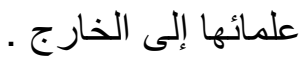

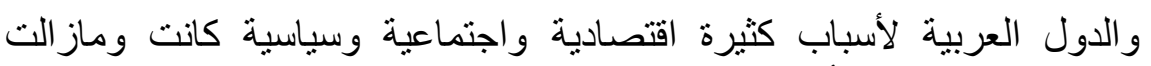

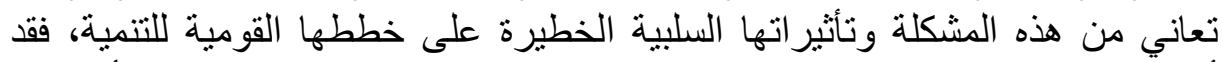

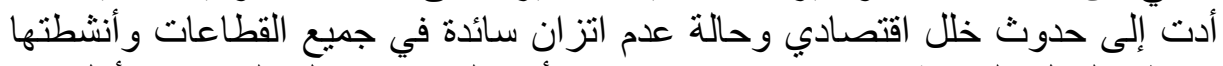

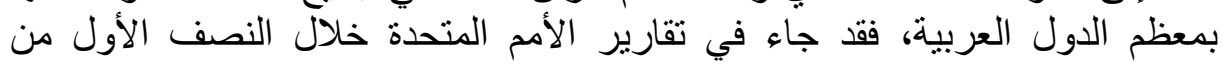

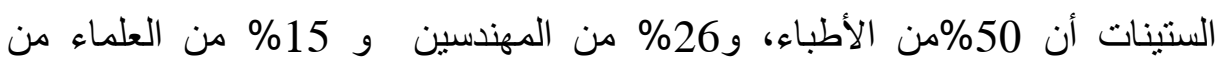

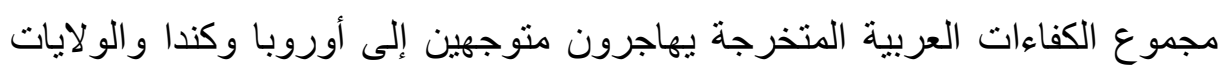

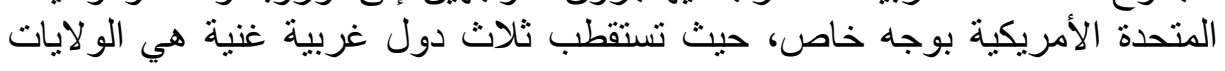

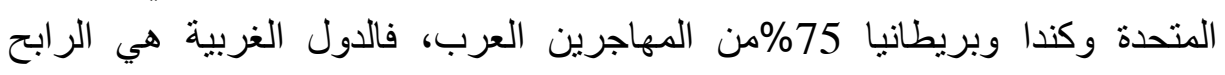


الأكبر من هجرة ما لا يقل عن 450 ألفا من العقول العربية، وتقدر خسائر الدول العربية من هذه الظاهرة بما لا يقل عن 200 مليار دو لار (20.).

بالإضافة إلى ما سبق فإن لهجرة العقول العربية تأثير ات سلبية كبيرة على عملية

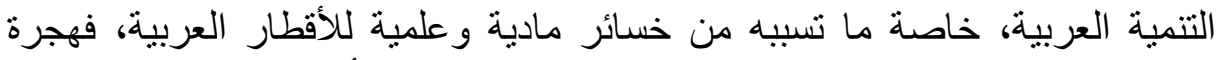
الكفاءات البشرية المتخصصة تفقد العرب موردا حيويا وأساسيا في ميدان تكوين القاعدة العلمية للبحث والتكنولوجيا، وتبدد الموارد المالية العربية الضخمة التهائ التي أنفقت

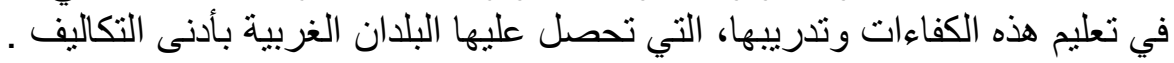

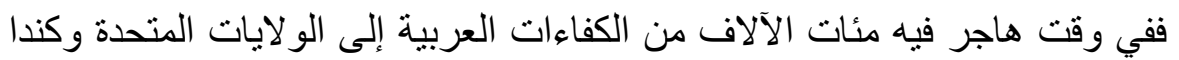

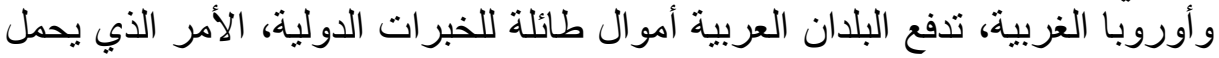
المشروعات الصناعية العربية تكاليف إضافية للخدمات الاستشارية و العمولات لات بنسبة الإلية

تتر اوح ما بين 200 - 300 \% مقارنة بالتكاليف الأولية (21).

$$
\text { ويمكن حصر أهم أسباب هجرة العقول و الكفاءات فيما يلي(22): }
$$

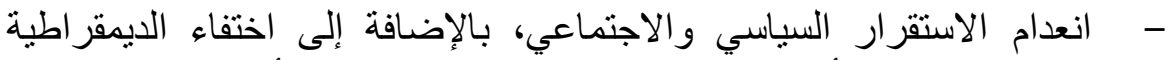

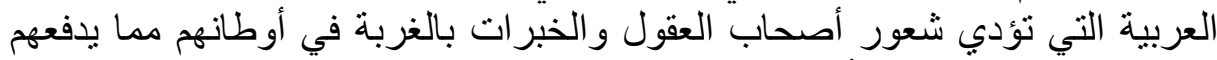

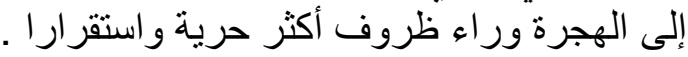

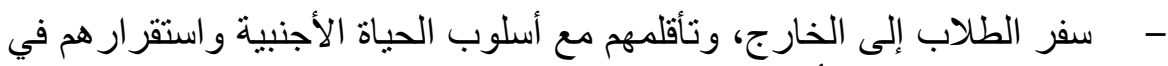

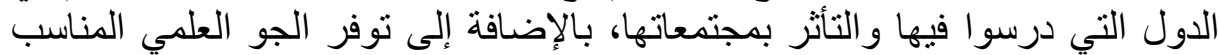
مقارنة بالموجود في بلادهم ـ مبات

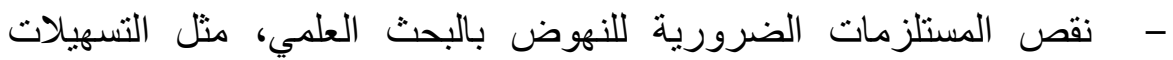

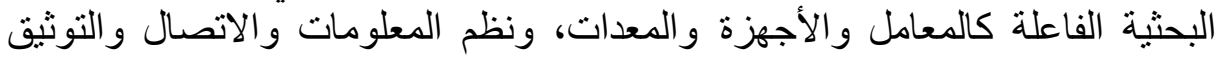
و الحاسبات الآلية... و غير ذلك. كالك.

- يعاني بعض العلماء العرب من انعدام وجود تخصصاء الغصاتهم كعلماء الذرة،

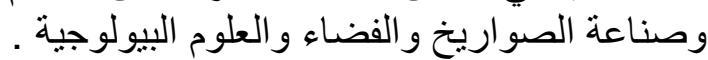

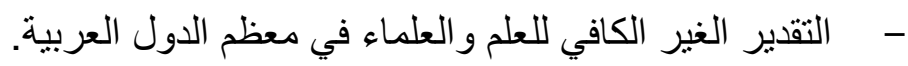
4- حلول مقترحة لمواجهة إثكالية البحث العلمي في الوطن العربي: أ- لول مقترحة لمواجهة إشكالية السيطرة السياسية :

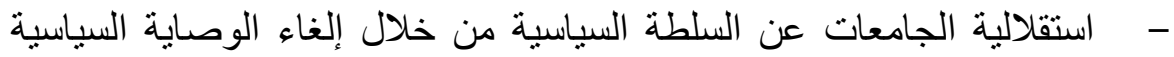

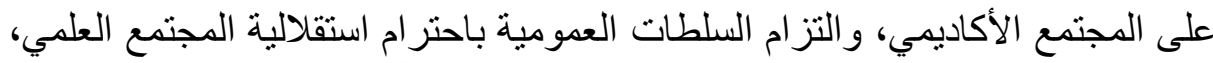

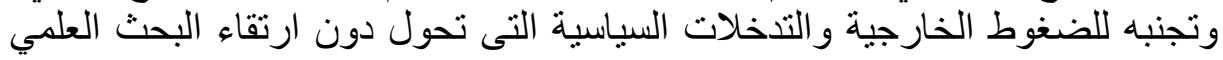


بها، مع احترام النتائج التي يتم التوصل إليها عن الأوضاع الاقتصادية والسياسية و الثقافية . - وضع اللوائح و النظم و التشريعات لحماية الملكية الفكرية .

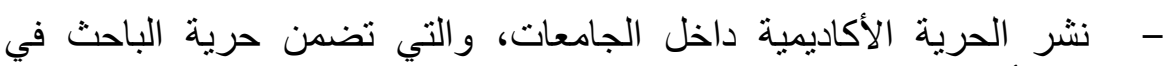

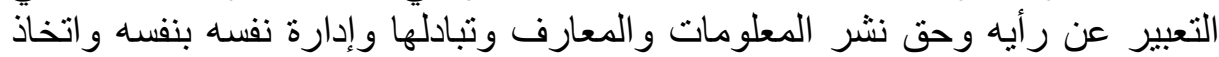

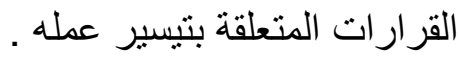

\section{ب- حلول مقترحة لمواجهة إثكالية ضعف التمله التمويل :}

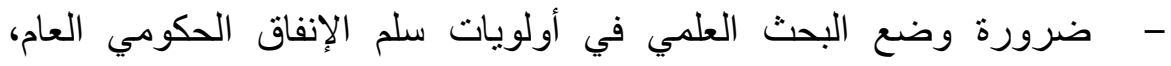

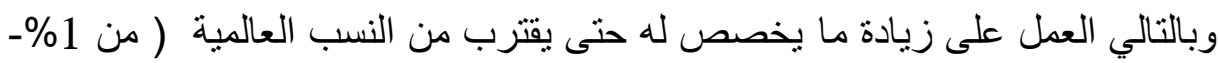

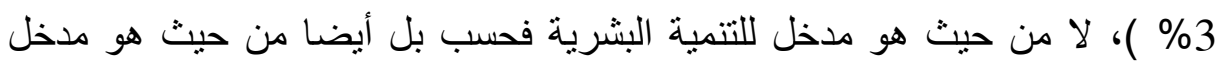

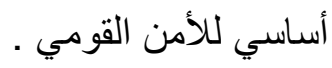

- - - استثمار الجهود الأهلية و الثعبية والنقابية استثمار ا صحيحا . - - مرح عدد من البدائل لتوفير سبل دعم التمويل اللازم للبحث العلمي مثل:

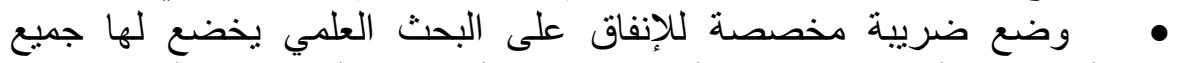

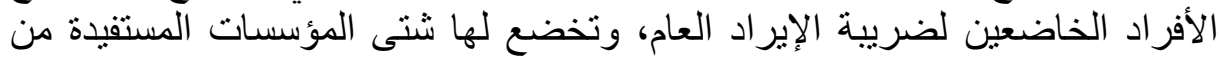
تشغيل خريجي مؤسسات التعليم المختلفة. • استخدام مؤسسات التعليم كوحدات إنتاجية .

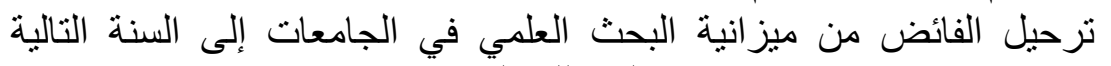

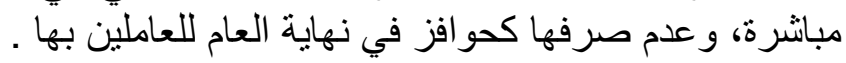

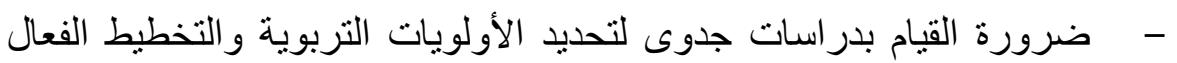

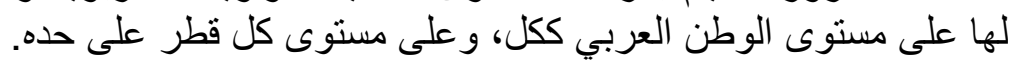

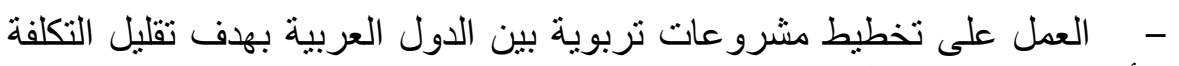

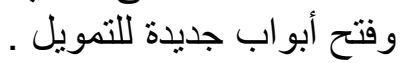

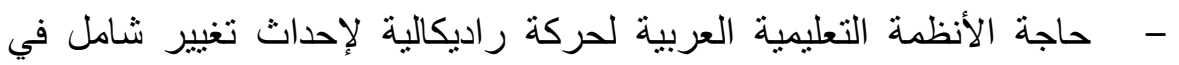

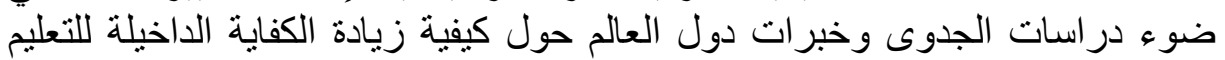
والبحث العلمي وتحقيق أقصى إنتاجية وبأقل تكلفة ممكنة .

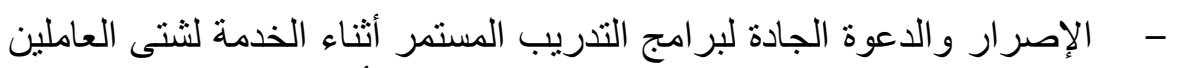

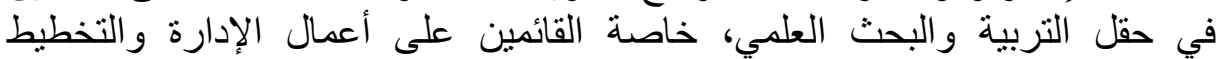

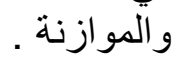

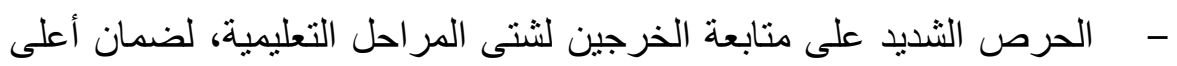

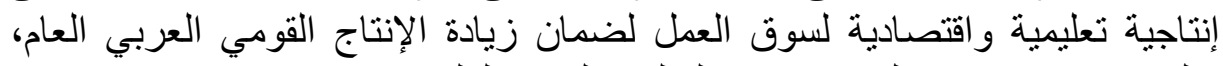
و الذي ينعكس بذوره على ميز انيات التعليم و البحث العلمي . 
- - - الحد من أسباب التي تؤدي بصورة مباشرة أو غير مباشرة لزيادة الإنفاق كما

إعادة النظر في الهيكل الإداري بما يخدم القضية، ويحد من الهذر ويسعى

للارتقاء بالميز انية .

يجب إعادة النظر في تنظيم أبواب الصرف في الميزانية لحل مشكلة بند

الرواتب والأجور و المكافآت التي تبتلع ما يقرب من 90 \% من المبرل الميزانية .

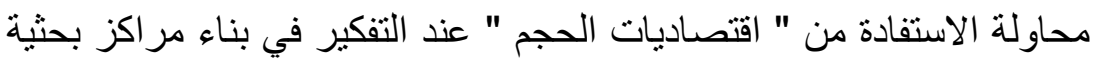
عملاقة مشتركة بين الأقطار.

محاولة الاستفادة من " اقتصاديات الوقت " في شتى البر امج البحثية.

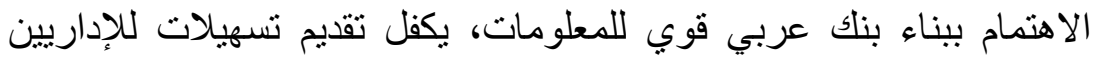
و الباحثين و المهتمين بالخطة و الموازنة و المتابعة .

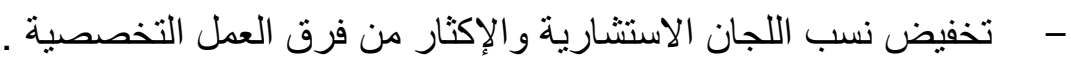

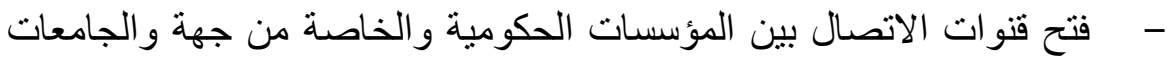

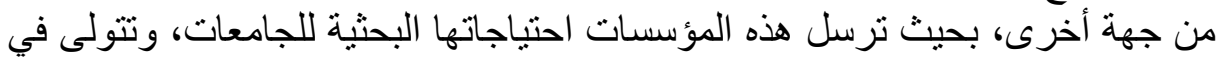

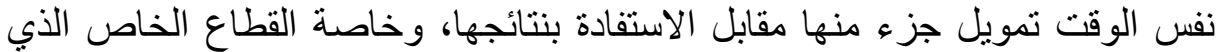

\section{ج- لول مقترحة لمواجهة إثكالية هجرة العقول وتوفير نظم العمل المشجعة}

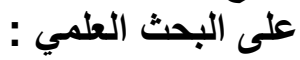

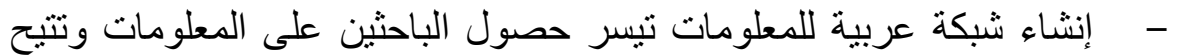
تبادل الآراء والأفكار، وتعزيز مشاركة الباحثين في المؤتمرات والينة الندوات العلمية

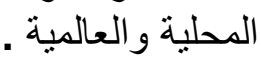

- - العمل على الحد من هجرة العقول بشتى صورها باعتبار هذه الهجرة تمثل

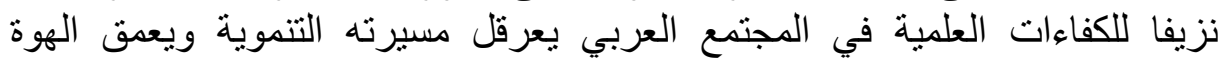
الحضارية والتكنولوجية بينه و بين المجتمعات الأخرى، وذللك بتوفير المناخ الملائم

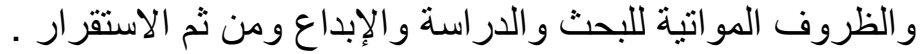

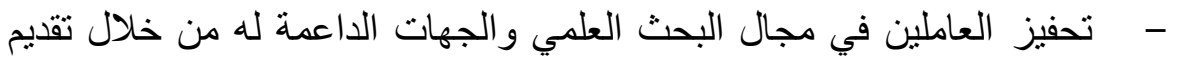
الجوائز والحوافز المادية والاحتفاء بالمتميزين لإعطائهم مزيدا من الدفع الماتهي المعنوي

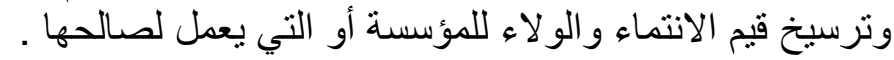

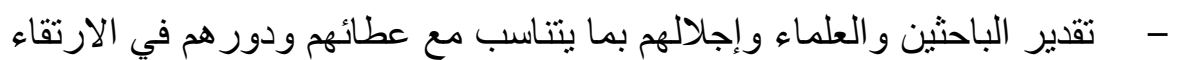

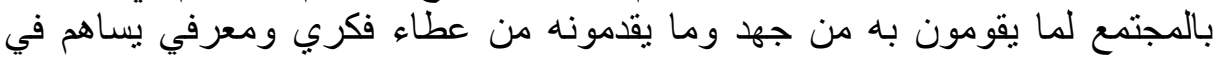
رقي الإنسان ورفاهيته.

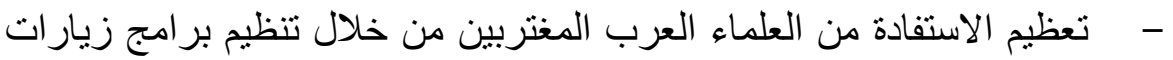
لأوطانهم لزيارة الجامعات المحلية والاستفادة بخبراتهم في تطوير البحث العند العلمي. 
الخـاتمـــة

- يعتبر البحث العلمي موردا مهما لاقتصاديات البلاد كالطاقة والموارد البشرية

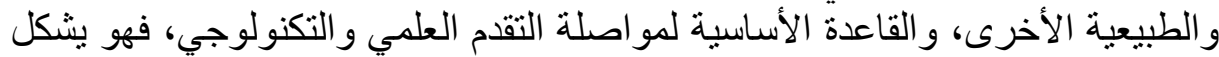

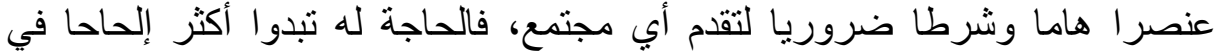

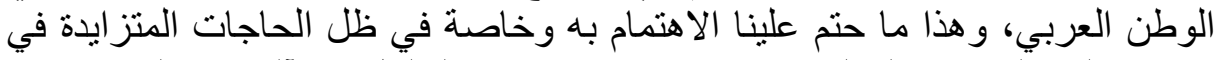

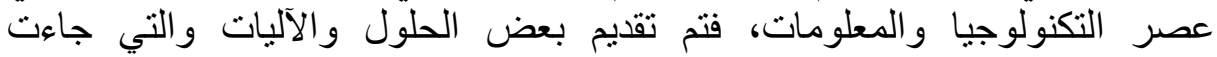

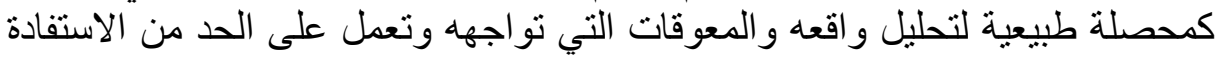

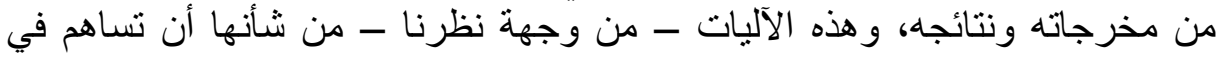

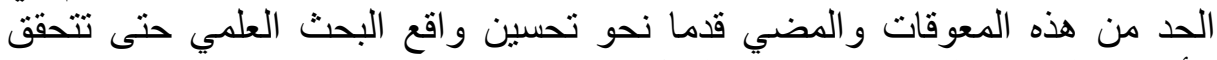
الأهداف المرجوة للارتقاء بشعوب الدوب الدول العربية.

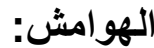

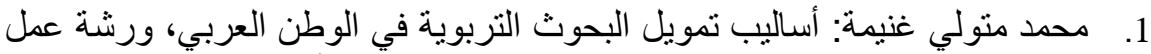

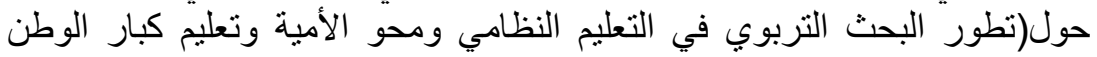

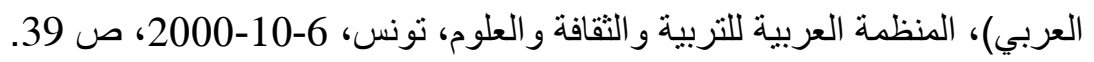

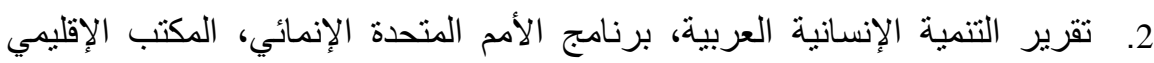

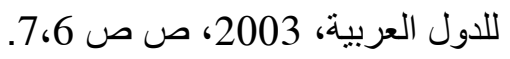

3. غازي حسين عناية: مناهج البحث، مؤسسة شباب الجامعة، الاسكندرية، مصر،

$$
\text { 1984، ص } 75 .
$$

4. فضيل دليو: أسس البحث وتقنياته في العلوم الاجتماعية -130 سؤالا وجو ابا، ديوان

المطبو عات الجامعية، قسنطينة، الجزائر، ص 15.

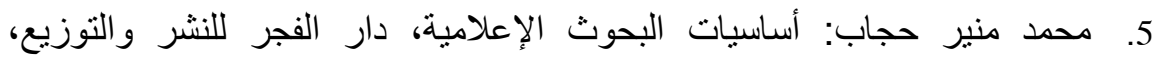

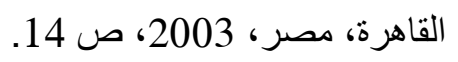

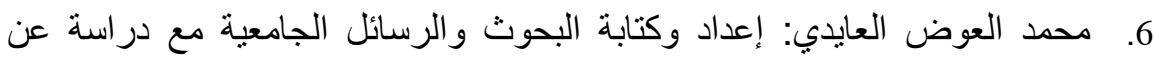

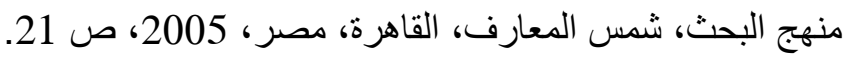

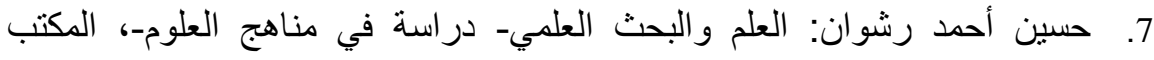

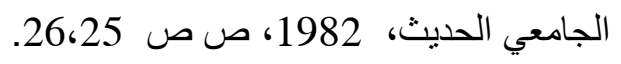

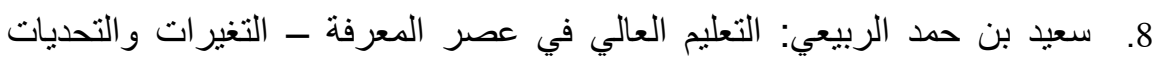

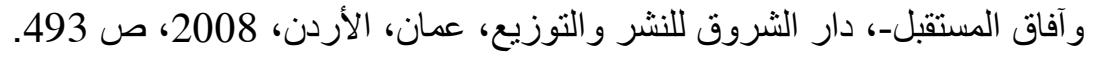

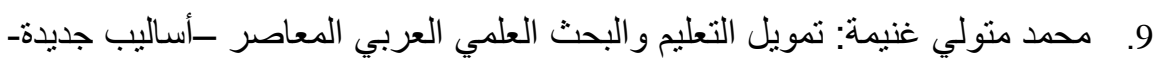

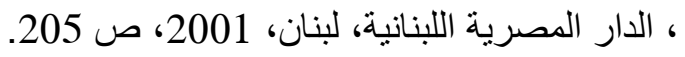


10. هام يعقوب مريزيق، فاطمة حسين الفقيه: قضايا معاصرة في التعليم العالي،

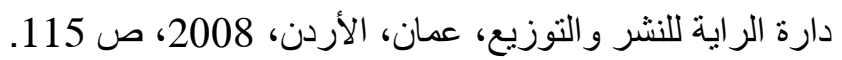

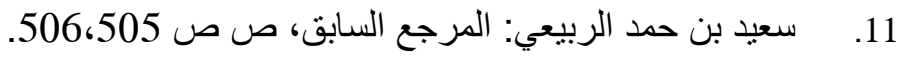

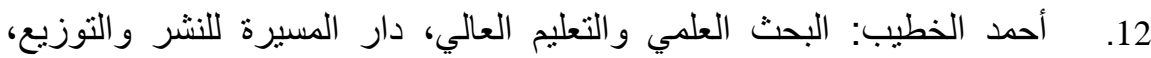

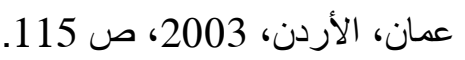

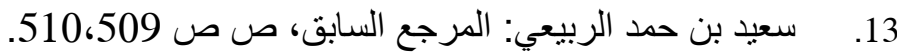

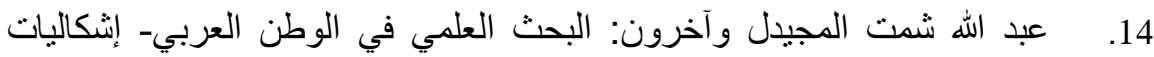

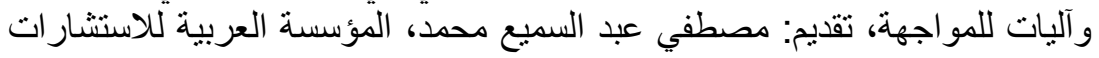

العلمية وتنمية الموارد البشرية، 2008، صلمانم 24.

15. تقرير التنمية الإنسانية العربية لعام 2003: مرجع سابق، ص 81.

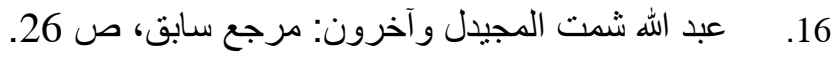

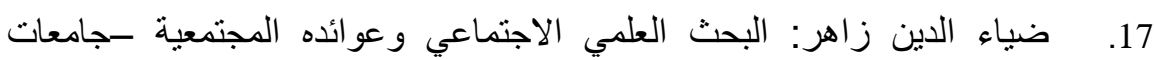

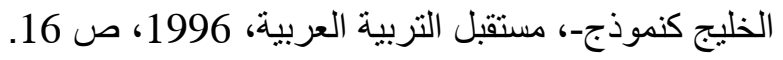

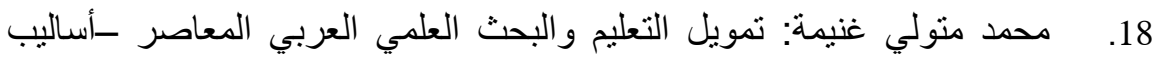

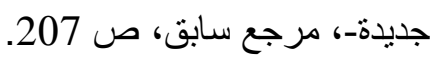

19.

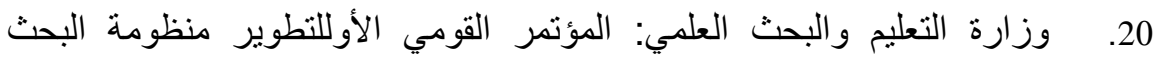

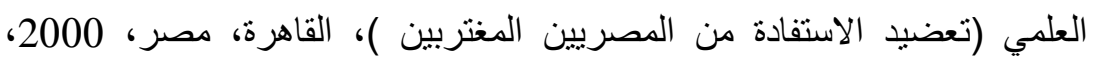

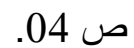

21. عبد الله شمت المجيدل وآخرون: مرجع سابق، ص 33.

22. المرجع نفسه ، ص34. 